\title{
$\mathrm{NaHCO}_{3}$ 의 혼주는 Rocuronium 정주로 인한 퉁중을 완화시킬 수 있다
}

\author{
연세대학교 의과대학 마취통증의학교실
}

한동우 · 구본녀 · 황세일 · 신양식 · 김기준

\section{Rocuronium Injection Pain is Attenuated by $\mathrm{NaHCO}_{3}$}

Dong Woo Han, M.D., Bon Nyeo Koo, M.D., Sae Il Hwang, M.D., Yang-Sik Shin, M.D., and Ki Jun Kim, M.D. Department of Anesthesiology and Pain Medicine, Yonsei University College of Medicine, Seoul, Korea

Background: Rocuronium administration is associated with a severe burning pain during injection. However, the mechanistic cause of the pain has not been well established. The purpose of this study was to determine whether adjusting the pH of the rocuronium with $\mathrm{NaHCO}_{3}$ would ameliorate the pain.

Methods: We examined mixtures using microscope after $\mathrm{NaHCO}_{3}$ was mixed with rocuronium to exam solubility. Sixty of 80 patients scheduled for elective gynecologic surgery were randomly allocated to one of three groups as follows: group 1 (rocuronium only, $\mathrm{n}=20$ ), group 2 (rocuronium $50 \mathrm{mg} / 5 \mathrm{ml}$ mixed with $0.9 \% \mathrm{NaCl} 3 \mathrm{ml}, \mathrm{n}=20$ ), group 3 (rocuronium 50 $\mathrm{mg} / 5 \mathrm{ml}$ mixed with $\mathrm{NaHCO}_{3} 3 \mathrm{ml}, \mathrm{n}=20$ ). All patients received $0.6 \mathrm{mg} / \mathrm{kg}$ of rocuronium over $10 \mathrm{sec}$ and were asked to assess pain using a visual analogue scale (VAS) followed by injection of propofol $1.5 \mathrm{mg} / \mathrm{kg}$ and fentanyl $100 \mathrm{mcg}$. The onset and duration of rocuronium were measured in three groups. Twitch responses to cumulative incremental doses of rocuronium were measured in another 20 patients, allocated to group A (rocuronium only, $\mathrm{n}=10$ ) or group $\mathrm{B}$ (rocuronium $50 \mathrm{mg} / 5 \mathrm{ml} \mathrm{mixed}$ with $\mathrm{NaHCO}_{3} 3 \mathrm{ml}, \mathrm{n}=10$ ).

Results: Over 24 hours, no precipitation or particles were found after mixing $\mathrm{NaHCO}_{3}$ with rocuronium. The VAS was significantly lower in group $3(0.5 \pm 0.9)$ than in group $1(5.4 \pm 3.2)$ or in group $2(4.9 \pm 2.1)(\mathrm{P}<0.05)$. Eighteen of 20 patients in group 3 had no pain and only 2 had mild pain, but all patients in groups 1 and 2 had mild to severe pain. There were no differences in onset or duration between the three groups and in twitch responses between group $\mathrm{A}$ and $\mathrm{B}$.

Conclusions: $\mathrm{NaHCO}_{3}$ mixed with rocuronium attenuates rocuronium injection pain, and there were no problems or complications. (Korean J Anesthesiol 2003; 45: 697 701)

Key Words: injection pain, $\mathrm{NaHCO}_{3}$, rocuronium.

\section{서 론}

Rocuronium bromide (rocuronium)는 aminosteroid 유도체인 비탈분극성 근이완제로서, 빠른 발현 시간의 장점 때문에

논문접수일 : 2003년 2월 17일

책임저자 : 김기준, 서울시 서대문구 신촌동 134 번지

연세대학교 의과대학 마취통증의학교실, 우편번호: $120-752$

Tel: 02-361-5847, Fax: 02-312-7185

E-mail: kkj6063@yumc.yonsei.ac.kr

본 연구는 제 47 차 대한마취과학회 추계학술대회(2002년, 한국)에서 발표하였음.

본 연구는 연세대학교 의과대학 2002년도 교수 연구비에 의해 이루어

졌음(과제 번호: 2002-19).
마취 유도 시 기관내 삽관을 용이하도록 하는 데에 많이 쓰인다. 그러나 이 약물은 정주 시 환자의 약 $50-80 \%$ 에서 통증을 일으킨다는 보고가 있다. ${ }^{1)}$ 통증은 적정 마취 유도제 의 투여에도 불구하고 정주하는 부위의 손이나 다리를 움 직일 정도로 심하고 10-20초간 지속되는 화끈화끈한(burning) 양상을 보이며, 깨어 있는 환자에게 priming 목적으로 기관내 삽관 용량의 $10 \%$ 를 정주할 때도 통증을 일으킨 다. ${ }^{1-3)}$

Rocuronium 정주통을 감소시킬 목적으로 국소 마취제나 아편 유사제의 사전 정주 등이 시도되어 왔으나, 그 효과는 다양하고 만족할 만한 성적은 흔치 않다. ${ }^{4-6)}$ 한편 시판되고 있는 rocuronium은 산도가 4.0이어서 이것이 통증을 유발하 는 한 요인으로 생각되기도 한다. ${ }^{45)}$ 그러나 rocuronium과 약 
물을 혼합하여 그 산도의 변화를 측정하거나, 혼합된 용액 의 정주 시에 통증의 감소 효과에 대해서 보고된 바는 없다.

이에 본 저자들은 $\mathrm{NaHCO}_{3}$ 를 혼합하여 rocuronium의 산도 를 조절함으로써 정주통을 감소시킬 수 있는지 확인해 보 고 그 통증의 원인을 유추해보고자 하였다.

\section{대상 및 방법}

본 연구는 본원 임상 연구 심의 위원회(Institutional review board, 승인번호 CR0256) 승인 하에 시행하였다.

\section{Study 1}

PH meter (pH meter model 420A, Orion Rearch Inc., USA) 를 사용하여 rocuronium $50 \mathrm{mg} / 5 \mathrm{ml}$ (Esmeron ${ }^{\circledR}$, 한국오가논) 의 $\mathrm{pH}$ 를 측정하고, rocuronium $50 \mathrm{mg} / 5 \mathrm{ml}$ 의 $\mathrm{pH}$ 를 7.4 로 만 드는데 필요한 $\mathrm{NaHCO}_{3}$ (광명 탄산수소나트륨 주사액 $8.4 \%{ }^{\circledR}$, 광명제약)의 적정량을 측정하기 위하여 $10 \mathrm{vial}$ 의 rocuronium 를 각각 한 번씩 사용하여 평균값을 구하였다. Rocuronium $50 \mathrm{mg} / 5 \mathrm{ml}$ 에 $\mathrm{NaHCO}_{3} 3 \mathrm{ml}$ 를 혼합하였을 때의 형태학적 변화의 관찰을 위해 혼합한 후 혼합 즉시, 5 분, 10 분, 30 분, 1 시간, 4시간, 12 시간, 24시간 후에 나타나는 변화를 육안 및 광학 현미경(× 400)으로 관찰하여 결정물이나 침전이 생기는지 확인하였다.

\section{Study 2}

전신 마취 하에 부인과 수술이 예정된 20-50세의 성인 여성으로 미국마취과학회 신체등급 분류 1,2 에 속하는 환 자 80명을 대상으로 하였다. 수술 전 방문 시 연구 목적과 방법에 대해 설명한 후, 환자 또는 보호자의 서면 동의서를 받았다.

80 명의 환자 중 60 명의 환자를 무작위로 세 군 $(1,2$ 및 3 군)으로 나누었으며, 각 군은 20 명씩으로 나이, 신장 및 체 중은 세 군간에 유의한 차이는 없었다(Table 1). 환자가 수 술실 도착 시에 자동혈압계, 심전도 및 맥박 산소 계측기를 부착하고, 자동 혈압계를 부착하지 않은 부위의 손등에 20 gauge 카테테르를 삽입하여 정맥로를 확보하고 하트만 용액 을 연결하였다. 1 군에서는 rocuronium만을 주사하였으며 2 군에서는 rocuronium $50 \mathrm{mg} / 5 \mathrm{ml}$ 에 $0.9 \%$ 생리식염수 $3 \mathrm{ml}$ 를 혼합한 용액을 주사하였고, 3군에서는 rocuronium $50 \mathrm{mg} / 5$ $\mathrm{ml}$ 에 $\mathrm{NaHCO}_{3} 3 \mathrm{ml}$ 를 혼합한 용액을 주사하였다. Rocuronium과 각 용액의 혼합은 환자에게 정주 직전에 혼합하였다.

각 군에서 확보된 정맥로를 통하여 10 초에 걸쳐 rocuronium $0.6 \mathrm{mg} / \mathrm{kg}$ 를 정주 후 VAS (Visual Analogue Scale, range: 0-10) 및 통증 정도를 ${ }^{7)}$ 확인하였다. 통증 정도의 판 정은 통증이 전혀 없는 경우를 0 점(무통), 통증 여부를 질문
Table 1. Demographic Data

\begin{tabular}{lcrr}
\hline Group & $1(\mathrm{n}=20)$ & $2(\mathrm{n}=20)$ & $3(\mathrm{n}=20)$ \\
\hline Age $(\mathrm{yr})$ & $38.1 \pm 10.7$ & $36.9 \pm 7.4$ & $43.0 \pm 8.3$ \\
Weight $(\mathrm{kg})$ & $52.3 \pm 7.2$ & $56.6 \pm 7.4$ & $56.3 \pm 6.8$ \\
Height $(\mathrm{cm})$ & $158.4 \pm 5.4$ & $158.9 \pm 5.2$ & $156.6 \pm 3.9$
\end{tabular}

All values are mean \pm SD. Group 1: rocuronium only, Group 2: rocuronium $50 \mathrm{mg} / 5 \mathrm{ml}$ mixed with $0.9 \% \mathrm{NaCl} 3 \mathrm{ml}$, Group 3: rocuronium $50 \mathrm{mg} / 5 \mathrm{ml}$ mixed with $\mathrm{NaHCO}_{3} 3 \mathrm{ml}$. There was no significant difference among three groups.

했을 때 통증을 느꼈다고 대답하나 행동을 나타내지 않는 경우를 1점(경도 통증), 자발적으로 통증을 호소하거나 행동 의 변화가 동반된 경우를 2점(중등도 통증), 강하게 통증을 호소하거나 얼굴을 찡그리고 팔을 움츠리거나 눈물을 흘리 는 등의 반응을 보이는 경우를 3점(심도 통증)으로 평가하 였다. 근이완 평가는 accelography (TOF-Watch ${ }^{\circledR} \mathrm{SX}$, Organon Teknica B.V., Boxtel, Netherlands)를 이용하였고, 손목의 척 골신경 주행 부위 피부 표면에 표면 전극을 부착 후 $2 \mathrm{~Hz}$, 4 연속자극을 12 초마다 가했을 때 나타나는 첫 번째 반응 $\left(\mathrm{T}_{1}\right)$ 을 rocuronium 정주 직후부터 측정하였다. VAS 및 통증 정도를 확인 후 $1 \%$ lidocaine이 $1 / 5$ 의 비율로 혼합된 propofol (1\% lidocaine $2 \mathrm{ml}+$ propofol $10 \mathrm{ml}$ ) $1.5 \mathrm{mg} / \mathrm{kg}$ 와 fentanyl $100 \mathrm{mcg}$ 을 정주하였으며, TOF 모니터상 $\mathrm{T}_{1}$ 이 사 라진 후에 기관내 삽관을 시행하였다. 마취는 sevoflurane 1.0-2.0 vol\%, $\mathrm{N}_{2} \mathrm{O} 5 \mathrm{O} \%$ 로 유지하였고, 호기말 이산화탄소 분압이 30-35 mmHg가 되도록 조절 환기를 하였다. Rocuronium의 작용 발현 시간은 rocuronium 정주 종료부터 TOF 의 $\mathrm{T}_{1}$ 이 사라지는 순간까지의 시간으로 하였으며, rocuroni$\mathrm{um}$ 의 작용 지속 시간은 $\mathrm{T}_{1}$ 이 사라진 순간부터 $\mathrm{T}_{1}$ 이 다시 나타나는 시간으로 하였다. 환자의 불편을 고려하여 rocuronium 정주 후 VAS 및 통증 정도를 확인하는 동안 환자가 호흡 곤란이나 눈꺼풀이 무거워지는 증상을 호소하면 연구 진행을 중단하고 즉시 propofol을 정주하여 마취유도를 하였 으며 이들을 연구에서 제외하였다.

80 명의 환자 중 나머지 20 명 환자를 무작위로 나누어 $\mathrm{A}$ 군 $(\mathrm{n}=10)$ 은 rocuronium을, $\mathrm{B}$ 군 $(\mathrm{n}=10)$ 은 rocuronium 50 $\mathrm{mg} / 5 \mathrm{ml}$ 과 $\mathrm{NaHCO}_{3} 3 \mathrm{ml}$ 혼합 용액을 정주하기로 하였다. Propofol을 정주 후 $\mathrm{N}_{2} \mathrm{O} 50 \%$ 와 sevoflurane $2 \mathrm{vol} \%$ 로 마취를 유지하였다. 손목 척골 신경 주행 부위 피부 표면에 표면 전극을 부착 후 $\mathrm{TOF}-\mathrm{Watch}{ }^{\circledR} \mathrm{SX}$ 를 이용하여 근 연축 반응이 안정화된 후, 두 군 환자에게 투여하기로 한 rocuronium $0.05 \mathrm{mg} / \mathrm{kg}$ 을 투여하였다. 연축 반응이 감소 후 5 회 이상 같은 크기를 유지하면, 동일한 방법으로 각각 $0.025,0.025$ $\mathrm{mg} / \mathrm{kg}$ 를 추가 투여하여 연축 높이의 변화를 관찰하였다. 술 
Table 2. Distribution of Pain Score

\begin{tabular}{cccc}
\hline & \multicolumn{3}{c}{ Group } \\
\cline { 2 - 4 } & $1(\mathrm{n}=20)$ & $2(\mathrm{n}=20)$ & $3(\mathrm{n}=20)$ \\
\hline 0 & 0 & 0 & $18^{*}$ \\
1 & 7 & 11 & $2^{+}$ \\
2 & 6 & 5 & $0^{*}$ \\
3 & 7 & 4 & $0^{*}$ \\
\hline
\end{tabular}

Values are numbers of patients according to pain score. Pain score 0 : negative response to questioning, 1: pain reported in response to questioning only without any behavioural signs, 2: pain reported in response to questioning and accompanied by a behavioural sign or pain reported spontaneously without questioning, 3: strong vocal response or response accompanied by facial grimacing, arm withdrawal, or tears. Group 1: rocuronium only, Group 2: rocuronium $50 \mathrm{mg} / 5 \mathrm{ml}$ mixed with $0.9 \% \mathrm{NaCl} 3 \mathrm{ml}$, Group 3: rocuronium $50 \mathrm{mg} / 5 \mathrm{ml}$ mixed with $\mathrm{NaHCO}_{3} 3 \mathrm{ml}$. *: $\mathrm{P}<0.05$ compared to group $1 \& 2 .{ }^{\dagger}: \mathrm{P}<0.05$ compared to group 2 .

후 80 명의 모든 환자에서 24시간 후 정맥로 주위 조직의 합병증(정맥염, 종창, 홍반, 통증 등) 유무를 관찰하였다.

통계 처리는 SPSS version 10.0 프로그램을 이용하였다. 통증 정도는 환자의 수로 표시하였고, 그 외 모든 측정치는 평균 \pm 표준편차로 표시하였다. 통증 정도는 Chi-square test, VAS는 Mann-Whitney U test를 이용하였고, 작용 발현 시간과 지속 시간은 ANOVA를 이용하였다. $\mathrm{P}<0.05$ 인 경 우 통계적으로 유의한 차이가 있는 것으로 판정하였다.

\section{결 과}

Rocuronium의 $\mathrm{pH}$ 는 $3.9 \pm 0.1$ 이었고, 중성화 시키는데 필 요한 $\mathrm{NaHCO}_{3}$ 의 적정량은 $3.1 \pm 0.3 \mathrm{ml}$ 이었다. Rocuronium $50 \mathrm{mg} / 5 \mathrm{ml}$ 에 $\mathrm{NaHCO}_{3} 3 \mathrm{ml}$ 를 혼합한 후 24시간까지 육안 및 광학 현미경 관찰상에서는 어떠한 결정이나 침전물도 관찰되지 않았다.

통증 정도는 1 및 2군의 모든 환자에서 경도 이상의 통 증을 호소한데 반해, 3 군에서는 20 명 중 18 명은 통증이 전 혀 없었고, 2 명만이 경도 통증을 호소하여 유의한 차이를 보였다 $(\mathrm{P}<0.05)($ Table 2). $\mathrm{VAS}$ 는 3 군에서 1,2 군에 비해서 유의하게 낮았다 $(\mathrm{P}<0.05)($ Table 3$)$.

작용 발현 시간과 지속 시간은 세 군간에 차이가 없었다 (Table 4). Rocuronium $0.05,0.025,0.025 \mathrm{mg} / \mathrm{kg}$ 투여 시 A 와 $\mathrm{B}$ 군간에 단순 연축 높이의 차이는 없었다(Table 5). 술 후 24시간까지 정맥로 주위 조직의 합병증은 모든 군에서 한 명도 관찰되지 않았다.
Table 3. Visual Analogue Scale (VAS)

\begin{tabular}{cccc} 
Group & $1(\mathrm{n}=20)$ & $2(\mathrm{n}=20)$ & $3(\mathrm{n}=20)$ \\
\hline VAS & $5.4 \pm 3.2$ & $4.9 \pm 2.1$ & $0.5 \pm 0.9^{*}$ \\
\hline
\end{tabular}

All values are mean \pm SD. Group 1: rocuronium only, Group 2: rocuronium $50 \mathrm{mg} / 5 \mathrm{ml}$ mixed with $0.9 \% \mathrm{NaCl} 3 \mathrm{ml}$, Group 3: rocuronium $50 \mathrm{mg} / 5 \mathrm{ml}$ mixed with $\mathrm{NaHCO}_{3} 3 \mathrm{ml}$. *: $\mathrm{P}<0.05$ compared to group $1 \& 2$.

Table 4. Onset and Duration of Neuromuscular Block

\begin{tabular}{lccc}
\hline Group & $1(\mathrm{n}=20)$ & $2(\mathrm{n}=20)$ & $3(\mathrm{n}=20)$ \\
\hline Onset $(\mathrm{sec})$ & $188.2 \pm 77.7$ & $169.4 \pm 59.5$ & $152.2 \pm 30.0$ \\
Duration (min) & $22.9 \pm 7.6$ & $27.5 \pm 7.6$ & $25.0 \pm 6.5$ \\
\hline
\end{tabular}

All values are mean \pm SD. Group 1: rocuronium only, Group 2: rocuronium $50 \mathrm{mg} / 5 \mathrm{ml}$ mixed with $0.9 \% \mathrm{NaCl} 3 \mathrm{ml}$, Group 3: rocuronium $50 \mathrm{mg} / 5 \mathrm{ml}$ mixed with $\mathrm{NaHCO}_{3} 3 \mathrm{ml}$. There was no significant difference among three groups.

Table 5. The Twitch Height after Injection of Rocuronium

\begin{tabular}{lccr} 
& $\mathrm{T}_{1}(\%)$ & $\mathrm{T}_{2}(\%)$ & $\mathrm{T}_{3}(\%)$ \\
\hline Group A $(\mathrm{n}=10)$ & $51.7 \pm 20.1$ & $24.6 \pm 15.1$ & $11.2 \pm 9.1$ \\
Group B $(\mathrm{n}=10)$ & $45.8 \pm 23.4$ & $17.4 \pm 10.9$ & $6.9 \pm 4.1$ \\
\hline
\end{tabular}

All values are mean \pm SD. Group A: rocuronium only, Group B: rocuronium $50 \mathrm{mg} / 5 \mathrm{ml}$ mixed with $\mathrm{NaHCO}_{3} 3 \mathrm{ml} . \mathrm{T}_{1}$ (\%): twitch height when 5 consecutive twitches of equal height were recorded after $0.05 \mathrm{mg} / \mathrm{kg}$ of rocuronium were administered, $\mathrm{T}_{2}(\%)$ : twitch height when 5 consecutive twitches of equal height were recorded after $0.025 \mathrm{mg} / \mathrm{kg}$ of rocuronium were administered following $T_{1}$, $\mathrm{T}_{3}$ (\%): twitch height when 5 consecutive twitches of equal height were recorded $0.025 \mathrm{mg} / \mathrm{kg}$ of rocuronium were administered following $\mathrm{T}_{2}$. There was no significant difference between two groups.

\section{고 찰}

본 연구에서 rocuronium을 단독 정주한 20 명의 모든 환자 에서 경도 이상의 정주통을 호소하였고, 이는 $\mathrm{NaHCO}_{3}$ 를 혼 합하여 중성화한 약제를 정주함으로써 통증의 빈도와 정도 를 감소시킬 수 있었다.

Rocuronium은 비탈분극성 근이완제로 발현 시간이 빨라 기관내 삽관을 용이하게 할 목적으로 자주 사용하고 있으 나, ${ }^{8,9)}$ 정주 시 통증이 심해 깨어 있는 환자의 priming이나 속상 수축 예방을 위해 사용하기에는 부적합하다. ${ }^{1-3)}$ 이러한 통증은 남성에 비해 여성에서 더욱 심한 통증을 호소하고 
그 빈도가 높은 것으로 알려져 있다.,10) 마취 유도 후에는 환자가 손목이나 팔꿈치를 갑자기 움츠리는 양상으로 관찰 되어지며, 그 정도는 통증의 강도와 비례하는 것으로 생각 된다. ${ }^{6,11)}$ 특히 나이가 적을수록 많이 관찰되며, ${ }^{6}$ 이러한 갑 작스러운 움직임은 정맥내 카테테르의 위치를 변형시킬 수 있을 뿐만 아니라 환자의 팔을 물리적인 힘으로 고정시켜 야 한다는 문제점들이 있다.

Dilek 등은 ${ }^{4)}$ ondansetron, lidocaine, tramadol 또는 fentanyl 을 사전 정주하였는데 lidocaine을 사전 정주한 집단에서 통 증 경감 효과가 가장 컸다고 보고하였다. Cheong과 Wong은 ${ }^{5}$ 사전 정주하는 lidocaine의 용량이 $10 \mathrm{mg}$ 일 때보다 $30 \mathrm{mg}$ 으 로 증량하였을 때 통증이 더욱 경감되었다고 보고하였다. 하지만 이런 보고들은 통증 유발의 원인을 차단하여 통증 유발을 방지시켰다기 보다는 증상 자체를 완화시킨 것이었 고, 이러한 약물들을 전처치하는 과정은 thiopental sodium이 나 propofol과 같은 정맥마취제를 투여 후 전처치를 해야하 므로 신속한 기관내 삽관이 요구되는 상황에서는 시간을 지연시켜 사용하기에 적절하지 않다. 또한 lidocaine과 같은 전처치 약물이 정주통 감소 효과를 나타내기 위해서는 상 완에 압박을 가하여 정맥 저류(retention) 상태를 만들어 일 정 시간 정맥 내에 머물러 있어야 하므로 번거로울 뿐 아 니라 더 많은 시간이 요구된다. ${ }^{12)}$

Rocuronium 정주통에 관한 기전은 아직까지 정확히 밝혀 져 있지 않다. Klement와 Arndt는 ${ }^{13)} \mathrm{pH}$ 가 4 이하이거나 11 이상의 약물을 정주할 때 통증을 유발할 수 있고 $\mathrm{pH}$ 가 극 단으로 갈수록 통증의 정도가 증가함을 보고하였다. Dhara 등은 ${ }^{14,15)}$ 마취 유도 전 vecuronium 정주 시에 정주통을 호소 함을 보고하였고, 이는 낮은 $\mathrm{pH}$ 때문이며 rocuronium 정주 통과 같은 기전일 것이라고 추측하였으나 이를 실제로 증 명하지는 못하였다. 반면 Borgeat와 Kwiatkowski는 ${ }^{2)} \mathrm{pH} 5.3$ 인 $0.9 \% \mathrm{NaCl}$ 을 $\mathrm{pH} 4.0$ 으로 적정하여 정주 시에 통증이 없 었음과 rocuronium 정주통을 일으킨 환자에게 30초 후 한번 더 rocuronium을 정주 시 통증이 감소함을 보고하여, rocuronium 정주통의 원인은 histamine, kinin과 같은 국소 매개 물(mediator)들의 분비에 의할 것이라고 주장하였다. 하지만 이들은 대상 환자가 5 명밖에 되지 않았으며, 또한 rocuronium을 두 번째 정주 시에도 통증의 정도만 감소하였을 뿐 통증은 5 명의 환자에서 여전히 관찰되었다. Rocuronium은 acetic acid나 sodium hydroxide의 첨가로 인하여 $\mathrm{pH}$ 가 4.0이 고, 등장성이 된다. ${ }^{89)}$ 본 연구에서 사용한 rocuronium의 $\mathrm{pH}$ 는 $3.9 \pm 0.1$ 이었으며, rocuronium만 들어있는 용액을 정주 한 군의 환자에서는 모두 정주통을 호소하였고 VAS는 5.4 인데 반해, rocuronium $50 \mathrm{mg} / 5 \mathrm{ml}$ 를 중성화시키기 위하여 $\mathrm{NaHCO}_{3} 3 \mathrm{ml}$ 를 혼합 후 정주한 군에서는 20 명의 환자 중 경도 통증을 호소한 2 명을 제외하고는 통증이 전혀 없었으
며 VAS는 $0.5 \pm 0.9$ 였다. 본 연구에서는 rocuronium 50 $\mathrm{mg} / 5 \mathrm{ml}$ 에 생리식염수 $3 \mathrm{ml}$ 를 혼합 후 $\mathrm{pH}$ 의 변화를 측정하 였었는데, $\mathrm{pH}$ 변화가 거의 없었음을 확인할 수 있었다. Rocuronium에 $0.9 \%$ 생리식염수를 혼합한 group에서의 통증 정도와 VAS가 rocuronium만을 정주한 group과 별 다른 차이 가 없었던 점을 고려할 때, 정주통 감소는 rocuronium 희석 효과가 아닌 $\mathrm{pH}$ 를 중성화시킨 효과에 기인한다고 생각할 수 있다.

말초 정맥에는 침해수용기(nociceptor)가 존재하며, ${ }^{16}$ 통증 의 강도는 통증 유발 약물이 예민한 정맥벽과 접촉하는 정 도에 좌우될 수 있다. Rocuronium을 전주와(antecubital fossa) 의 굵은 정맥을 통하여 정주 시 통증이 감소된 보고는 ${ }^{17}$ rocuronium이 굵은 정맥내 혈류의 한 가운데로 흐르면서 그 만큼 정맥벽에 닿을 기회가 줄어들기 때문일 것이다. ${ }^{18)}$ 본 연구에서는 rocuronium 단독 정주 시 20 명의 모든 환자에서 정주통을 호소하여 다른 연구 결과들에 비해 ${ }^{1)}$ 정주통의 빈 도가 훨씬 큰 것으로 나타났는데, 이는 정맥로가 가는 손등 부위 정맥을 선택하여 rocuronium을 10 초의 빠른 속도로 정주하였기 때문에 낮은 산도의 rocuronium이 혈관 내벽에 존재하는 침해수용기를 더욱 쉽게 자극하였을 것으로 생각 된다.

본 연구 도중 rocuronium 정주 후 VAS 및 통증 정도를 확인하는 동안 호흡 곤란이나 눈꺼풀이 무거워지는 증상이 의심되어 중단된 예는 없었으며, 어떤 환자에서도 심전도와 맥박 산소 포화도의 변화는 관찰되지 않았다. Rocuronium을 $\mathrm{NaHCO}_{3}$ 와 혼합한 후 24시간 동안 관찰했으나 어떠한 침전 물이나 색상 변화 등의 발생은 없었다. 근 이완의 발현 시 간과 지속 시간 측정 시, $1 \mathrm{~Hz}$ 의 단순 연축 반응이 아닌 $\mathrm{TOF}$ 자극을 이용하였기 때문에 $\mathrm{T}_{1}$ 을 12 초 간격으로 측정한 데 따른 오차의 발생 가능성을 전혀 배제할 순 없겠지만 근 이완의 발현 시간과 지속 시간이 세 군에서 차이가 없 었고, rocuronium을 $\mathrm{NaHCO}_{3}$ 와 혼합 정주 시 단순 연축 반 응의 감소 정도가 rocuronium 단독 정주 시와 차이가 없었 던 것으로 보아 $\mathrm{NaHCO}_{3}$ 와 혼합하여 정주한 rocuronium의 물리적, 약리적인 특성에는 특별한 변화가 없었음을 유추할 수 있다.

결론적으로, rocuronium 산도를 중성화시킴으로써 rocuronium의 정주통을 감소시킬 수 있었으며, 따라서 rocuronium 정주통의 원인으로서 낮은 산도를 생각할 수 있다.

\section{참 고 문 헌}

1. Steegers MA, Robertson EN: Pain on injection of rocuronium bromide. Anesth Analg 1996; 83: 203.

2. Borgeat A, Kwiatkowski D: Spontaneous movements associated 
with rocuronium: is pain on injection the cause? $\mathrm{Br} \mathrm{J}$ Anaesth 1997; 79: 382-3.

3. Moorthy SS, Dierdorf SF: Pain on injection of rocuronium bromide. Anesth Analg 1995; 80: 1067.

4. Dilek M, Alparslan T, Beyhan K, Necdet S, Zafer P: The prevention of pain from injection of rocuronium by ondansetron, lidocaine, tramadol, and fentanyl. Anesth Analg 2002; 94: 1517-20.

5. Cheong KF, Wong WH: Pain on injection of rocuronium: influence of two doses of lidocaine pretreatment. Br J Anaesth 2000; 84: 106-7.

6. Borgeat A, Kwiatkowski D, Ruetsch YA: Spontaneous movements associated with rocuronium injection: The effects of prior administration of fentanyl. J Clin Anesth 1997; 9: 650-2.

7. McCrirrick A, Hunter S: Pain on injection of propofol: the effect of injectate temperature. Anaesthesia 1990; 45: 443-4.

8. Mayer M, Doenicke A, Hofmann A, Peter K: Onset and recovery of rocuronium (Org 9426) and vecuronium under enflurane anaesthesia. Br J Anaesth 1992; 69: 511-2.

9. Bartowski RR, Witkowski TA, Azad S, Lessin J, Marr A: Rocuronium onset of action: a comparison with atracurium and vecuronium. Anesth Analg 1993; 77: 574-8.

10. Mencke T, Beerhalter U, Fuchs-Buder T: Spontaneous movements, local reactions and pain on injection of rocuronium. A comparison between female and male patients. Acta Anaesthesiol Scand 2001; 45: 1002-5.

11. Ruetsch YA, Borgeat A: Withdrawal movements associated with the injection of rocuronium. Anesth Analg 2000; 90: 227-8.

12. Shevchenko Y, Jocson JC, McRae VA, Stayer SA, Schwartz RE, Rehman M, et al: The use of lidocaine for preventing the withdrawal associated with the injection of rocuronium in children and adolescents. Anesth Analg 1999; 88: 746-8.

13. Klement W, Arndt JO: Pain on I.V. injection of some anesthetic agents is evoked by the unphysiological osmolality or $\mathrm{pH}$ of their formulations. Br J Anaesth 1991; 66: 189-95.

14. Ti LK, Dhara SS: Vecuronium, like rocuronium, causes pain on injection. Br J Anaesth 1998; 81: 487.

15. Kent AP, Bricker SRW, Coleman P: Pain during injection of vecuronium. Anaesthesia 1988; 43: 334.

16. Arndt JO, Klement W: Pain evoked by polymodal stimulation of hand veins in humans. J Physiol (Lond) 1991; 440: 467-78.

17. Dalgleish DJ: Drugs which cause pain on intravenous injection. Anaesthesia 2000; 55: 828-9.

18. Tan $\mathrm{CH}$, Onsiong MK: Pain on injection of propofol. Anaesthesia 1998; 53: 468-76. 